\title{
Spatial patterns in infection of cod Gadus morhua with the seal-associated liver worm Contracaecum osculatum from the Skagerrak to the central Baltic Sea
}

\author{
Maria Sokolova ${ }^{1}$, Kurt Buchmann ${ }^{2}$, Bastian Huwer ${ }^{1}$, Per W. Kania ${ }^{2}$, Uwe Krumme ${ }^{3}$, \\ Anders Galatius ${ }^{4}$, Jakob Hemmer-Hansen ${ }^{5}$, Jane W. Behrens ${ }^{1, *}$ \\ ${ }^{1}$ National Institute of Aquatic Resources, Technical University of Denmark (DTU Aqua), Kgs. Lyngby 2800, Denmark \\ ${ }^{2}$ Department of Veterinary and Animal Sciences, Faculty of Health and Medical Sciences, University of Copenhagen, \\ Frederiksberg C 1870, Denmark \\ ${ }^{3}$ Thünen Institute of Baltic Sea Fisheries, 18069 Rostock, Germany \\ ${ }^{4}$ Department of Bioscience, Aarhus University, Roskilde 4000, Denmark \\ ${ }^{5}$ National Institute of Aquatic Resources, Technical University of Denmark (DTU Aqua), Silkeborg 8600, Denmark
}

\begin{abstract}
Fish serve as transport hosts to a range of parasites, with potential negative effects on fish health. In the Baltic Sea, the grey seal Halichoerus grypus (Fabricius) population has increased markedly since the early 2000s. H. grypus is the main final host to the liver worm Contracaecum osculatum (Rudolphi, 1802), a parasitic nematode to which cod Gadus morhua (Linnaeus) is one of several transport hosts. Recent investigations have shown a marked increase in prevalence and abundance of infection of this parasite in livers of G. morhua inhabiting the central Baltic Sea. Yet no recent knowledge exists on levels of C. osculatum infection in G. morhua in adjacent areas. We investigated spatial differences in prevalence and abundance of this parasitic nematode in livers of G. morhua, covering a transect consisting of 9 areas from the Skagerrak to the eastern part of the central Baltic Sea. We further provide survey data of local abundances of H. grypus and harbour seal Phoca vitulina (Linnaeus) throughout this transect. Prevalence and abundance of C. osculatum sensu stricto in G. morhua livers differed significantly between east and west, with highest levels of infection occurring in the low-salinity central Baltic areas. Fish in the east had significantly lower condition than their westerly conspecifics. Spatial differences in local seal abundance and seal species, salinity and feeding ecology may explain the observed differences in C. osculatum infection between eastern and western G. morhua.
\end{abstract}

KEY WORDS: Parasitic nematode $\cdot$ Species interactions $\cdot$ Salinity $\cdot$ Transport host $\cdot$ Condition factor $\cdot$ Feeding ecology $\cdot$ Grey seal $\cdot$ Harbour seal

\section{INTRODUCTION}

Fish serve as transport hosts to a range of parasites, which often possess complex life cycle strategies. These parasites may negatively affect fish health, which facilitates transmission to the subsequent host (Barber et al. 2000). At times, the parasite-induced effects act conjointly with other stressors (Marcogliese \& Pietrock 2011). However, usually the ulti-

*Corresponding author: jabeh@aqua.dtu.dk

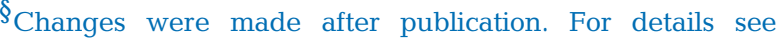
www.int-res.com/abstracts/meps/v606/c_p105-118/

This updated version: December 12, 2018 mate consequences of specific parasites on the health of fish stocks are difficult to assess.

In the Baltic Sea, grey seals Halichoerus grypus (Fabricius) are among the top predators, and their role in the ecosystem and potential effects on local fish stocks are presently heavily debated. Their population has increased markedly since the beginning of the 2000s to around 30000 individuals counted on the haul-out sites in 2017 (Hårding et al. 2007, ICES

(C) The authors 2018. Open Access under Creative Commons by Attribution Licence. Use, distribution and reproduction are unrestricted. Authors and original publication must be credited.

Publisher: Inter-Research · www.int-res.com 
WGMME 2018). In the Baltic region, H. grypus is the main final host to the liver worm Contracaecum osculatum (Rudolphi, 1802), a parasitic nematode to which cod Gadus morhua (Linnaeus) is one of several transport hosts (Valtonen et al. 1988, Lunneryd et al. 2015, Zuo et al. 2018). Recent investigations have shown a marked increase in the prevalence and intensity of infection for this parasite in G. morhua of the central Baltic Sea as compared to estimates from the 1980s when $H$. grypus abundance was lower and distribution was narrower (Buchmann \& Kania 2012, Haarder e al. 2014, Mehrdana et al. 2014, Nadolna \& Podolska 2014, Zuo et al. 2018). Larger-sized G. morhua are infected with third-stage C. osculatum larvae by eating smaller infected fish, e.g. sprat Sprattus sprattus (Linnaeus), their main fish prey in the central Baltic (Zuo et al. 2016). When ingested, the larvae penetrate the stomach of G. morhua and then migrate to the liver (hence the common name 'liver worm') where they become encapsulated, a typical host reaction towards larger pathogens (Haarder et al. 2014, Dezfuli et al. 2016a,b, Zuo et al. 2017). In some areas, e.g. in the Western Bornholm Basin and along the Polish coast, single livers may contain several hundred C. osculatum larvae, causing structural changes to the organ (Mehrdana et al. 2014, Horbowy et al. 2016, Zuo et al. 2018).

G. morhua in the Baltic Sea are divided into 2 stocks, i.e. eastern and western. The eastern Baltic stock (inhabiting mainly the central Baltic) thrived in the early 1980 s, decreased gradually to low levels over the following decades and showed signs of a recovery in the mid-2000s, which has been attributed to changes in fishing pressure and environmentally mediated recruitment success (Eero et al. 2015, Köster et al. 2017). However, a gradual deterioration of individual nutritional condition accompanied the increase in their numbers, together with a virtual disappearance of larger fish from the stock. It remains unclear if this is due to increased natural mortality, reduced growth or a combination of both (Eero et al. 2015, Casini et al. 2016, Horbowy et al. 2016). The role of seal-associated liver infection of G. morhua with C. osculatum may play a role in this situation, but major ecological linkages in the system are still unclear. However, considering that the liver controls various essential metabolic functions and constitutes the main energy reserve for fish, the high infection levels are potentially one factor (among others) involved in the current decrease in nutritional status of G. morhua in the central Baltic Sea (Eero et al. 2015). Many C. osculatum in the liver may ultimately result in increased natural mortality (Horbowy et al.
2016). Notably, increased nematode parasite infection due to spread of infective stages from seals was observed in G. morhua in Newfoundland and Labrador (Canada) before the collapse of those stocks (Brattey et al. 1990).

The core distribution area of $H$. grypus is in the central Baltic between latitudes $58^{\circ} \mathrm{N}$ and $61^{\circ} \mathrm{N}$, where $85 \%$ of the moulting seals were counted in 2003 (Hårding et al. 2007). With increasing abundance, the distribution has expanded as well, particularly to the south and west (HELCOM 2017, Olsen et al. 2018). Thus, in 2017, approximately 2700 individuals of $H$. grypus were counted south of $58^{\circ} \mathrm{N}$ in Sweden, Denmark, Germany and Poland (HELCOM unpubl. data). Furthermore, $H$. grypus are very mobile animals and have been observed to move from the Danish Baltic to breeding haul-outs in Estonia (Dietz et al. 2015). Given the re-colonization and expanding range linked to high mobility, these marine mammals may be expected to spread C. osculatum throughout the Baltic Sea. While the recent increase of infection with C. osculatum in the central Baltic around Bornholm is well documented (Mehr-

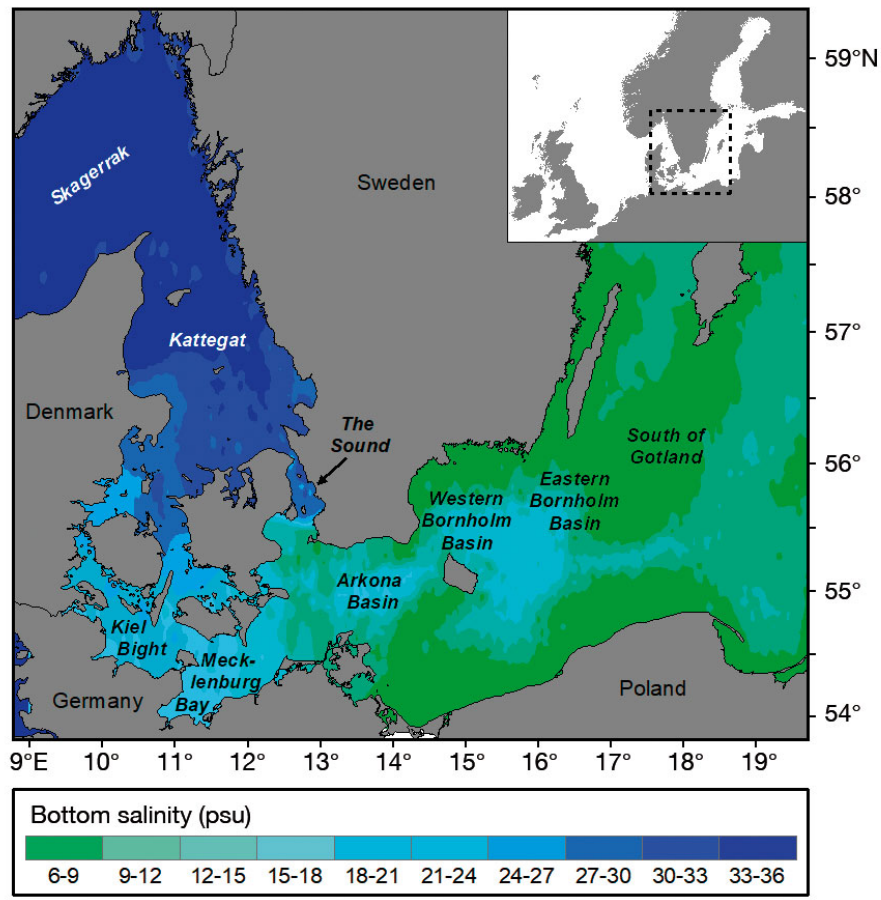

Fig. 1. Nine areas where cod Gadus morhua were sampled for analysis of liver worm Contracaecum osculatum, covering a transect from the Skagerrak at the northern entrance to the Danish straits to the eastern part of the central Baltic Sea. Distribution of bottom water salinities is shown (based on the ICES Dataset on Ocean Hydrography; http://ocean. ices.dk/HydChem/HydChem.aspx?plot=yes) 
dana et al. 2014, Eero et al. 2015), it remains presently uncertain to what extent G. morhua are infected with C. osculatum in adjacent areas towards the west and east. Such knowledge has major implications for our general understanding of factors controlling parasite load and how infection may affect individual fish health and eventually stock status and dynamics.

The aim of the present study was therefore to investigate prevalence and abundance of infection of C. osculatum in adult G. morhua from 9 different areas, thoroughly covering a transect from the Skagerrak to the central Baltic Sea, including the Danish straits, the western Baltic and the Arkona Basin (Fig. 1). We further compared the condition of G. morhua between areas and relate the spatial patterns of infection prevalence and severity to survey data providing local abundances of $H$. grypus and harbour seal Phoca vitulina, another known final host for C. osculatum. We finally discuss how the differences observed between areas may relate to differences in abiotic (salinity) and biotic factors (seal abundance, differences in prey fields and resulting feeding ecology).

\section{MATERIALS AND METHODS}

\section{Study areas and fish collection}

Gadus morhua were caught in 9 selected areas, covering a transect from the Skagerrak to the central part of the Baltic Sea: Skagerrak, Kattegat, the Sound, Kiel Bight, Mecklenburg Bay, Arkona Basin and the central Baltic areas, i.e. western and eastern parts of the Bornholm Basin and south of Gotland (Fig. 1). Fish were sampled in quarter 4 of 2016 (Skagerrak, Kattegat, the Sound, 3 areas in central Baltic) and quarter 4 of 2017 (Kiel Bight, Mecklenburg Bay and Arkona Basin) mainly by bottom trawling during scientific surveys or scientific investigations on commercial vessels, but also via gillnets and pound nets (Mecklenburg Bay, Kiel Bight) (Table 1). To account for the restricted size range of $G$. morhua encountered in the eastern Baltic Sea (G. morhua $>50 \mathrm{~cm}$ total length [TL] are presently rare) and to ensure comparability between areas, only G. morhua within the size range of 35 to $50 \mathrm{~cm}$ TL were used in the analysis ( $\mathrm{n}=321$ in total). The smallest size of $35 \mathrm{~cm}$ was chosen because the proportions of G. morhua in the central Baltic infected with Contracaecum osculatum increase rapidly in fish above $30-35 \mathrm{~cm}$ (Zuo et al. 2016). We also attempted to keep the size range relatively narrow, as infection intensity increases

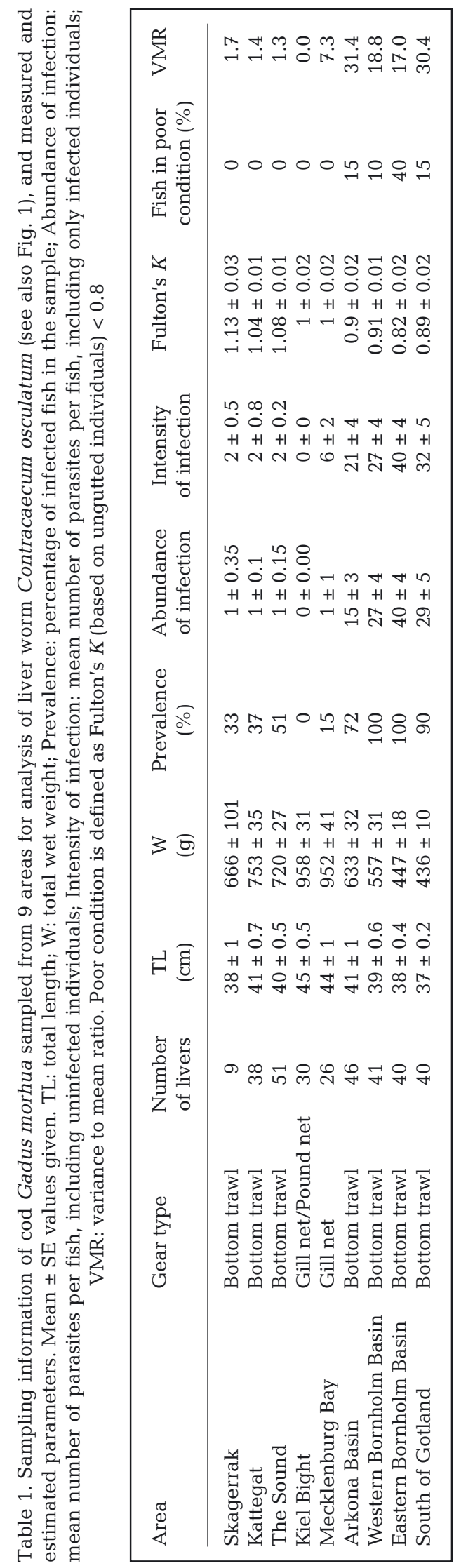


with fish length, at least in the Baltic proper (Horbowy et al. 2016). In this way, a potential effect of differences in fish size among areas was minimized.

G. morhua were either (1) immediately frozen whole onboard (Kattegat, the Sound and the 3 central Baltic areas) and then thawed and processed in the laboratory following routine procedures (determination of TL, whole-fish wet weight, sex, removal of liver), (2) transported fresh to the laboratory and processed there (Kiel Bight, Mecklenburg Bay) or (3) processed onboard (Skagerrak, Arkona Basin). Upon processing, individual livers were kept at $-20^{\circ} \mathrm{C}$ for subsequent analysis of the number and species of nematodes.

\section{Analysis of livers for nematodes}

All analyses of livers for the presence of parasitic nematodes were performed at the Laboratory of Aquatic Pathobiology, University of Copenhagen (Frederiksberg, Denmark). Individual livers were thawed, placed in plastic bags $(200 \times 400 \times 0.07 \mathrm{~mm})$ between 2 glass plates $(15 \times 15 \times 1 \mathrm{~cm})$ and compressed to $1 \mathrm{~mm}$ thickness by adding gentle pressure to the plates (Buchmann 2007). Livers were examined under a Leica stereo microscope (6.3-40× magnification) (Leica Microsystems Germany), and detected nematodes were rinsed in tap water and isolated in Petri dishes. The nematode species identification was based on morphometric characteristics of the caudal and cephalic ends according to Fagerholm (1982). After species identification, nematodes were stored in $96 \%$ ethanol (Kemetyl) in V-bottom $50 \mathrm{ml}$ plastic tubes for subsequent molecular identification.

For all areas, prevalence of infection (percentage of infected fish in the sample), abundance of infection (mean number of parasites per host, including both infected and uninfected individuals), and intensity of infection (mean number of parasites per host, including only infected individuals) were calculated according to Bush et al. (1997). The $15 \mathrm{~cm}$ size range was not further stratified and means refer to a sampled area. Furthermore, Fulton's $K$ was calculated as $F=\left(\frac{W}{L^{3}}\right) \times$ 100 , where $W$ is the wet weight $(\mathrm{g})$ of the whole fish and $L$ is TL (cm) (Ovegård et al. 2012). The proportion of G. morhua in poor nutritional condition, i.e. with Fulton's $K<0.8$ (Marteinsdottir \& Begg 2002) was determined for each area. Finally, the variance to mean ratio (VMR) was calculated as $\mathrm{VMR}=\frac{\sigma^{2}}{\mu}$, where $\sigma^{2}$ is the sample variance and $\mu$ is a mean value of the number of parasites per individual fish (Upton \& Cook 2006).

\section{Genetic analysis of parasites}

For verification of the nematode species and type, PCR and sequencing were performed for the internal transcribed spacer (ITS) region and the cytochrome oxidase subunit II (COX2) gene, respectively. A subsample of 24 worms from the Sound, in addition to 5 nematodes from Skagerrak and south of Gotland that were unidentifiable by morphometric analysis) were selected for molecular analysis of the ITS region. Further, a subsample of 9 worms from the Kattegat and 1 worm from Skagerrak were selected for molecular analysis of the COX2 in order to differentiate between types of $C$. osculatum. Parasite tissue (the middle part of each individual) was incubated in 10x lysis buffer (100\% Tween20, $0.5 \mathrm{ml}$ EDTA, Trisbaze, $\mathrm{H}_{2} \mathrm{O}$, Proteinase $K$, Qiagen) at $55^{\circ} \mathrm{C}, 500 \mathrm{rpm}$ for $2 \mathrm{~h}$. Complete tissue digestion was subsequently confirmed by light microscopy. Following lysis, Proteinase $K$ was inactivated by heating the sample to $95^{\circ} \mathrm{C}$ for $10 \mathrm{~min}$.

Species diagnosis was performed by sequencing the ITS and the type diagnosis by sequencing the COX2. In the case of ITS, NC5 (5'-GTA GGT GAA CCT GCG GAA GGA TCA TT-3') [10 $\mu \mathrm{M}]$ was used as forward primer, and NC2 (5'-TTA GTT TCT TTT CCT CCG CT-3') $[10 \mu \mathrm{M}]$ as reverse primer. The mitochondrial gene COX2 was amplified using 211F (5'TTT TCT AGT TAT ATA GAT TGR TTY AT-3') $[10 \mu \mathrm{M}]$ and 210R (5-CAC CAA CTC TTA AAA TTA TC-3') $[10 \mu \mathrm{m}]$ as forward and reverse primers, respectively. Both regions were amplified in a $60 \mu \mathrm{l}$ reaction volume per sample containing $10 \times \mathrm{PCR}$ buffer, dNTP $(4 \times 10 \mathrm{mM}), \mathrm{MgCl}_{2}(1.5 \mathrm{mM}), \mathrm{H}_{2} \mathrm{O}$, polymerase (Bioline) and the template. PCR conditions of the ITS region and the COX2 gene were the same as reported by Zhu et al. (2007) and Zuo et al. (2018), respectively. PCR products were analysed by agarose gel electrophoresis in ethidium bromide stained $1 \%$ agarose gels and subsequently purified using the Illustra ${ }^{\mathrm{TM}}$ GFX ${ }^{\mathrm{TM}}$ PCR DNA purification kit (GE Healthcare) and sequenced (Macrogen Korea). The obtained sequences were analysed using the software CLC Main Workbench v7.9.1 (Qiagen) and confirmed by a BLAST ${ }^{\circledR}$ search of GenBank.

Maximum likelihood phylogenetic analysis (1000 bootstraps) was performed using the COX2 gene. The sequence alignment was achieved by ClustalW. The model GTR+G+T was chosen, as this model was the best choice in 3 of 4 tests (Akaike's information criterion [AIC], AIC corrected for small sample sizes [AICc] and the Bayesian information criterion [BIC]). The fourth test (hierarchical likelihood ratio test) had the $\mathrm{HKY}+\mathrm{G}+\mathrm{T}$ as the first choice and GTR+G+T as 
the second choice. The sequences obtained in this study were compared to a series of other Contracaecum species and their subtypes (C. osculatum A, B, D, sensu stricto [s.s.] and $E_{;}$GenBank accession nos. EU477203-7, respectively) together with $C$. radiatum (EU477213), C. omorhini (EU477211), C. margolisi (EU477212), C. moroungae (EU477213), C. rudolphii A (EF535570) and C. rudolphii B (EU852349). The 2 nematodes Pseudoterranova ceticula (DQ116435) and Ascaris suum (X54253) were used as the outgroup.

\section{Genetic analysis of $G$. morhua from the Arkona Basin}

G. morhua from the Arkona Basin were analysed with genetic markers to identify population of origin (Eero et al. 2014), as this geographical region is an area of mixing between eastern and western Baltic cod populations (Eero et al. 2014, Hüssy et al. 2016). Here, we used 187 single nucleotide polymorphisms (SNPs) that provided high statistical power for assigning fish to either of the 2 Baltic populations (Nielsen et al. 2012). We used fish collected at spawning time from eastern and western Baltic populations as base lines and assigned fish from the Arkona region through a Bayesian approach (Rannala \& Mountain 1997) implemented in the program GeneClass2 (Piry et al. 2004). Individuals were assigned based on maximum assignment scores (ratio of assigned sample likelihood to the sum of all likelihoods), and 2 individuals with assignment scores below $99 \%$ were excluded from the analyses.

\section{Abundance of Halichoerus grypus and Phoca vitulina in the Baltic Sea}

Haul-out counts during the respective moulting seasons of $H$. grypus and $P$. vitulina were used as proxies for seal distribution. Seals may be distributed differently between seasons, and haul-out use during the moulting season does not translate directly to distribution patterns at sea. However, we assume that haul-out counts constitute an approximation of at-sea distribution of seals, at a level of accuracy that is adequate in the context of this study, where parasite life cycle completion depends on a significant presence of suitable final hosts in the area. Haul-out counts of seals were collected following Galatius et al. (2014). To avoid bias caused by fluctuations during a single year, data from 2015-2017 were used. For Sweden, 2015-2016 estimates were used since data for 2017 were not yet available.
For $H$. grypus and $P$. vitulina, during the moulting season each locality was counted 1-3 and 2-3 times, respectively. The average of the 2 highest counts for a given locality in a given year (or the single count) was used to calculate the average, to minimize the effects of, e.g., disturbance of the haul-out prior to the count.

The study area included $H$. grypus from 2 populations, which overlap, but have different moulting and breeding seasons (Fietz et al. 2016). Data from Fietz et al. (2016) indicate that seals originating from the North Sea make up the majority of $H$. grypus in the Kattegat, while in the Danish Baltic, most H. grypus are of Baltic origin. Thus, survey data collected during the North Sea moulting season in March-April were used for the Kattegat, while data from the Baltic moulting season in May-June were used elsewhere. $P$. vitulina surveys were conducted during their moulting season in August.

H. grypus individuals are not counted during their moulting season along the Swedish west coast, so the absence of this seal species along this coastline in our data does not mean that $H$. grypus are absent from that area. However, data on $H$. grypus presence and abundance in this area were collected during moult surveys for $P$. vitulina in August.

\section{Statistical analysis}

An ANOVA of the linear model (Eq. 1) was used to examine if there was any difference in fish length $\left(L_{l}\right.$ $\mathrm{cm})$ between areas, where area $\left(\beta_{\text {area }_{i}}\right)$ was used as a descriptive variable, and subscripts $l$ and $i$ denote the individual fish and different areas, respectively:

$$
\widehat{L_{1}}=\beta_{\text {area }_{i}}
$$

In order to test dependence of abundance of infection $\left(\widehat{\mu}_{1}\right), 4$ different variables were included in the generalized linear model (GLM) of negative binomial family: Fulton's $K\left(F_{i}\right)$ and length $\left(L_{l}\right)$ as continuous variables, and sex $\left(\delta_{\text {sex }_{i}}\right)$ and area $\left(\beta_{\mathrm{area}_{i}}\right)$ as categorical variables:

$$
\widehat{\mu_{1}}=\alpha_{1} F_{i}+\alpha_{2} L_{i}+\beta_{\text {area }_{i}}+\delta_{\text {sex }_{i}}
$$

Further, the significance of each parameter was tested through a likelihood ratio test. Thus, the final model (Eq. 3) contained $F_{i}, L_{i}$ and $\beta_{\mathrm{area}_{i}}$ as descriptive variables:

$$
\widehat{\mu_{1}}=\alpha_{1} F_{i}+\alpha_{2} L_{i}+\beta_{\text {area }_{i}}
$$

The differences in abundance of infection between separate study areas were analysed and illustrated through visualization of model predictions. 
Examination of the difference in the prevalence of infection $\left(\widehat{\eta}_{1}\right)$ between areas was obtained using a likelihood ratio test of GLM of the binomial family containing $F_{i}, L_{i}$ and $\beta_{\text {area }_{i}}$ as descriptive variables:

$$
\widehat{\eta}_{1}=\alpha_{1} F_{i}+\alpha_{2} L_{i}+\beta_{\text {area }_{i}}
$$

and the model without area as a descriptive variable:

$$
\widehat{\eta}_{1}=\alpha_{1} F_{i}+\alpha_{2} L_{i}
$$

where prevalence was G. morhua coded as ' 1 ' for infected fish and ' 0 ' for not-infected fish. The statistical tests were carried out in R version 3.3.2. (www.Rproject.org).

\section{RESULTS}

Sex was not significant ( $p>0.05)$ when testing for significance of the descriptive parameters (sex $\left[\operatorname{sex}_{i}\right]_{\text {, }}$ length $\left[L_{i}\right]$, Fulton's $K\left(F_{i}\right)$ and area [area $\left.{ }_{i}\right]$ ) on the mean abundance and prevalence of infection. Hence, sex was removed from the subsequent models (models 3 and 5, respectively).

TL of sampled fish was significantly higher in the western areas (Kiel Bight and Mecklenburg Bay) as compared to the other areas $(p<0.05)$, and there was a significant negative correlation between TL and abundance of infection. In contrast, no significant differences in abundance of infection between male and female fish was found in any of the areas ( $p>0.05)$ (Table 1).

The nematodes belonged to the species Contracaecum osculatum as determined by sequencing of the ITS region. Further sequencing and phylogenetic analysis of the mitochondrial gene COX2 revealed that the nematodes were of the $C$. osculatum s.s. type.

\section{Prevalence and abundance of $C$. osculatum}

The prevalence of infection with C. osculatum differed significantly between areas $(\mathrm{p}<$ 0.05). While it was $90-100 \%$ in the 3 central Baltic areas, it was $33-51 \%$ in the Sound, Kattegat and Skagerrak, and lowest in the Mecklenburg Bay and Kiel Bight (15 and $0 \%$, respectively). The Arkona Basin (72\%) was intermediate between the eastern and northwestern areas (Table 1, Figs. 2 \& 3A). A similar trend was found for the abundance of infection (Table 1, Figs. 2 \& 3B): it was highest in the eastern areas, i.e. western and eastern parts of Bornholm Basin and south of Gotland, lower in the Skagerrak, Kattegat and the Sound, and lowest in the southwestern Baltic (Kiel Bight and Mecklenburg Bay). Most infected were livers of Gadus morhua from the eastern Bornholm Basin, where two-thirds of the livers carried $\geq 20$ parasites; 32 and $55 \%$ of the livers from the western Bornholm Basin and south of Gotland contained $>30$ worms (Fig. 2). The abundance in the Arkona Basin was intermediate, being significantly lower than in the central Baltic areas, but significantly higher than in the Skagerrak, Kattegat, the Sound, Kiel Bight and Mecklenburg Bay (Fig. 3B). However, a different picture emerged when G. morhua sampled in the Arkona Basin were split into fish of western and eastern origin based on the genetic analyses. Of the 46 fish from the Arkona Basin that could be assigned based on genetics, 13 were assigned to the western and 33 to the eastern stock. Notably, the abundance of infection with $C$. osculatum in their livers was significantly higher for the fish assigned to the eastern stock $(21 \pm 4 \mathrm{C}$. osculatum, mean $\pm \mathrm{SE}$ ) as compared to the western stock $(1 \pm 1)(\mathrm{p}<0.01)$.

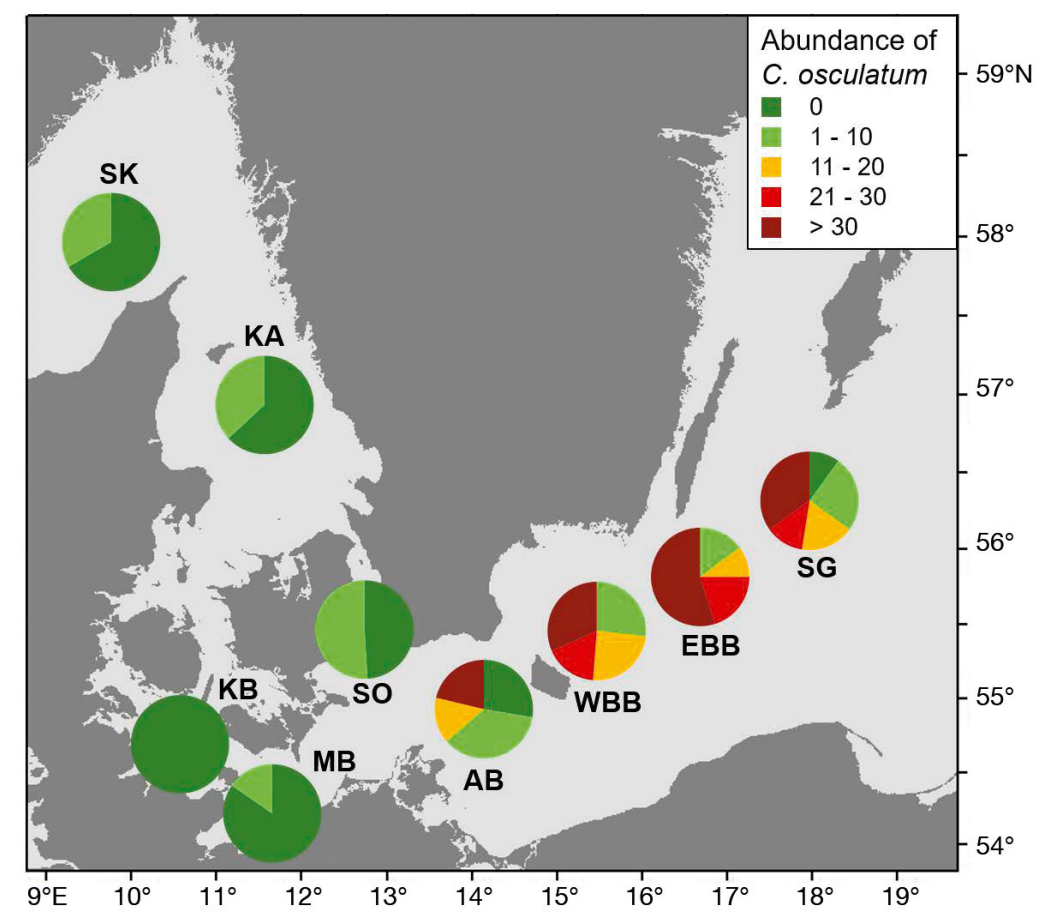

Fig. 2. Abundance of Contracaecum osculatum infection (mean number of parasites per liver of Gadus morhua, including uninfected individuals) in the 9 study areas: Skagerrak (SK), Kattegat (KA), the Sound (SO), Kiel Bight (KB), Mecklenburg Bay (MB), Arkona Basin (AB), Western Bornholm Basin (WBB), Eastern Bornholm Basin (EBB) and south of Gotland (SG) 


\section{Fulton's condition factor, $K$}

G. morhua from the western areas with low infection were in good nutritional condition (average Fulton's $K \geq 1.0$, no fish with Fulton's $K \leq 0.8$ ). In contrast, a substantial proportion of the more heavily parasitized eastern conspecifics from the Arkona Basin and eastwards were in poor nutritional condition, i.e. with Fulton's $K<0.8$. Specifically, $15,10,40$ and $15 \%$ of G. morhua from the Arkona Basin, the western and eastern Bornholm Basin, and South of Gotland, respectively, had Fulton's $K<0.8$ (Table 1). The overall trend in Fulton's $K$ across areas was opposite to the trends for the area-specific abundance of infection with C. osculatum (Fig. 4). For the Arkona Basin alone, G. morhua assigned to the east-

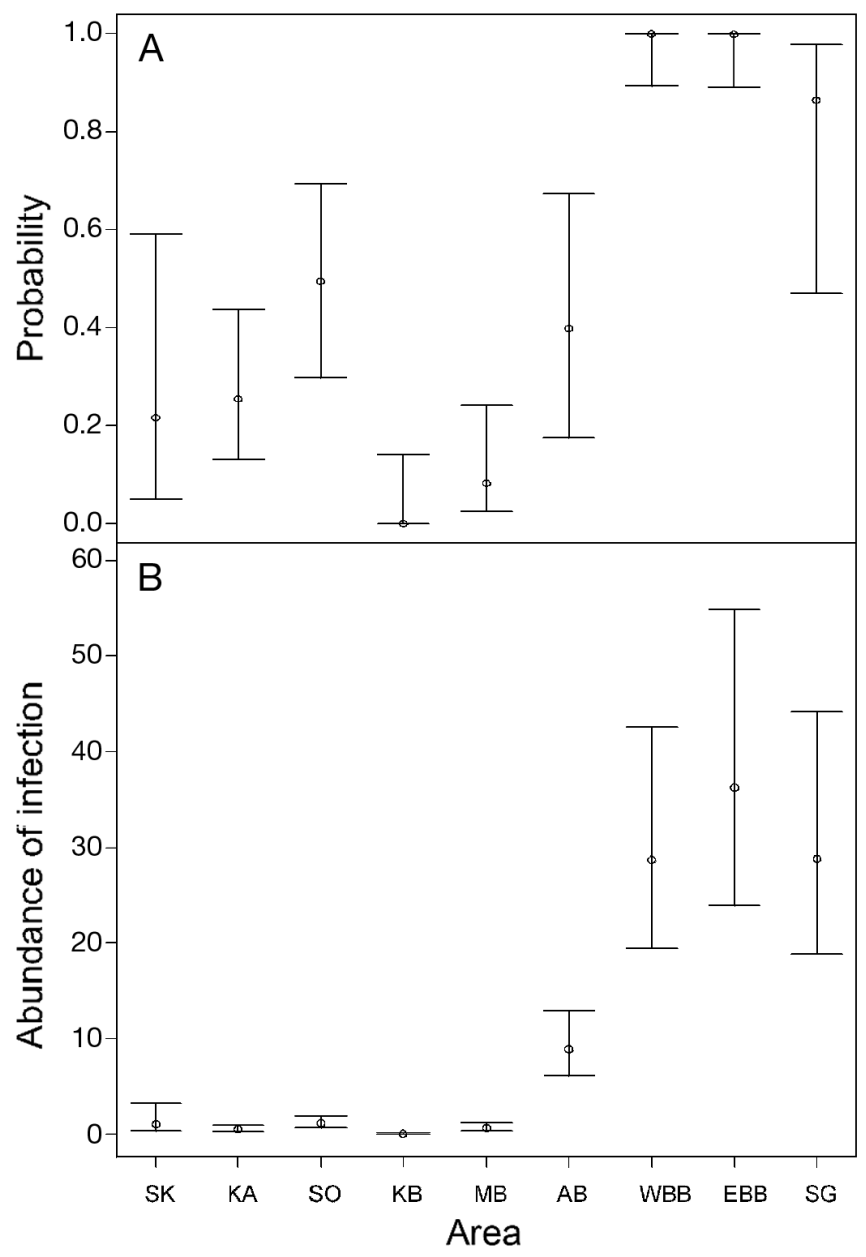

Fig. 3. Generalized linear modelling results from predictions of (A) log prevalence of infection (percentage of infected fish in the sample) in the 9 study areas (output from model 4 ) and (B) the abundance of infection (mean number of parasites per Gadus morhua, including uninfected individuals; output from model 3). Mean $\pm 95 \%$ confidence intervals are shown. Area abbreviations as in Fig. 2 ern stock had significantly lower Fulton's $K$ (average = $0.9)$ than their conspecifics from the western stock (average $=1.0)(p<0.05)$.

\section{Frequency distributions of $C$. osculatum}

Except for the eastern Bornholm Basin, where the majority of G. morhua livers contained 21-30 C. osculatum, most fish from all other areas had 0-10 parasites in their livers (Fig. 5). In fact, in Skagerrak, Kattegat, the Sound, Kiel Bight and Mecklenburg Bay, no G. morhua carried more than 10 parasites. In contrast, most livers from the 3 areas in the central Baltic contained higher and highly variable numbers of parasites. Some individual livers of $G$. morhua had up to 121-130 parasites (Fig. 5). This resulted in a highly overdispersed frequency distribution and was also reflected in high VMR values (17.0-30.3, Table 1). Also, the Arkona Basin displayed high variability of infection (but at an intermediate level) with 30 out of 47

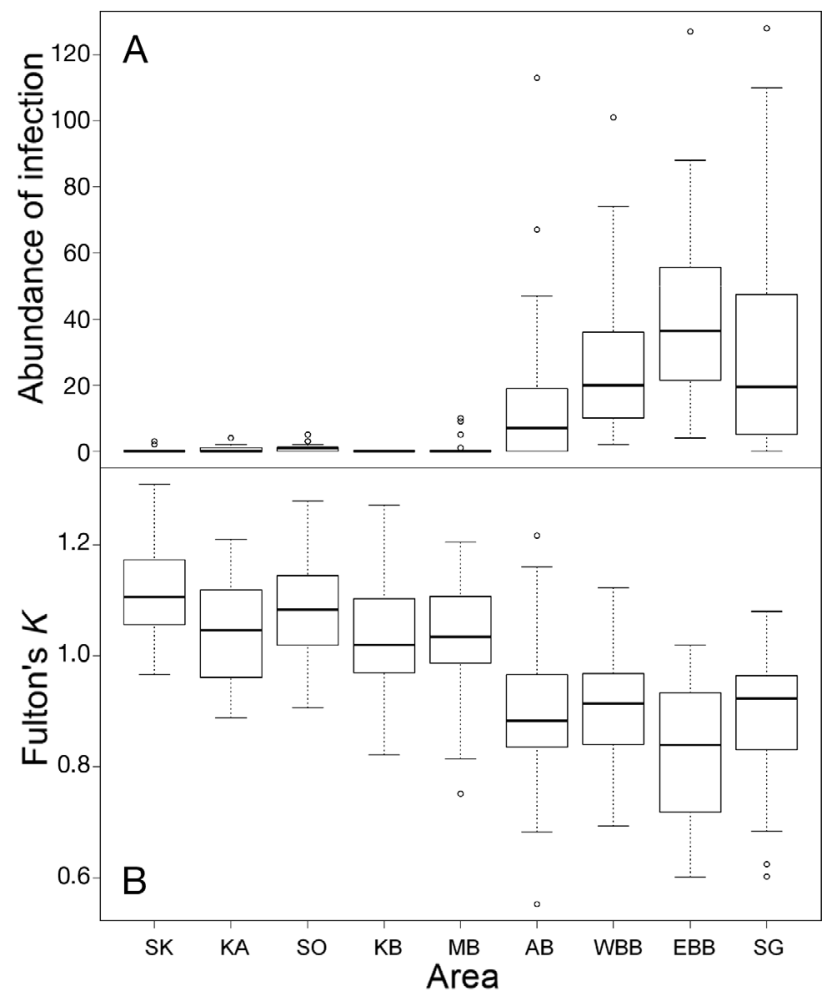

Fig. 4. (A) Abundance of Contracaecum osculatum infection (mean number of parasites per liver of Gadus morhua including uninfected individuals) in G. morhua livers. (B) Fulton's $K$ of $G$. morhua from the 9 areas. Area abbreviations as in Fig. 2. Solid line: median; box: interquartile range (IQR), where bottom and top are 25 th and 75 th percentiles, respectively; whiskers: max/min observation if within 1.5 of the IQR, or $1.5 \times$ IQR. Circles: observations not covered in the area between the whiskers (outliers) 


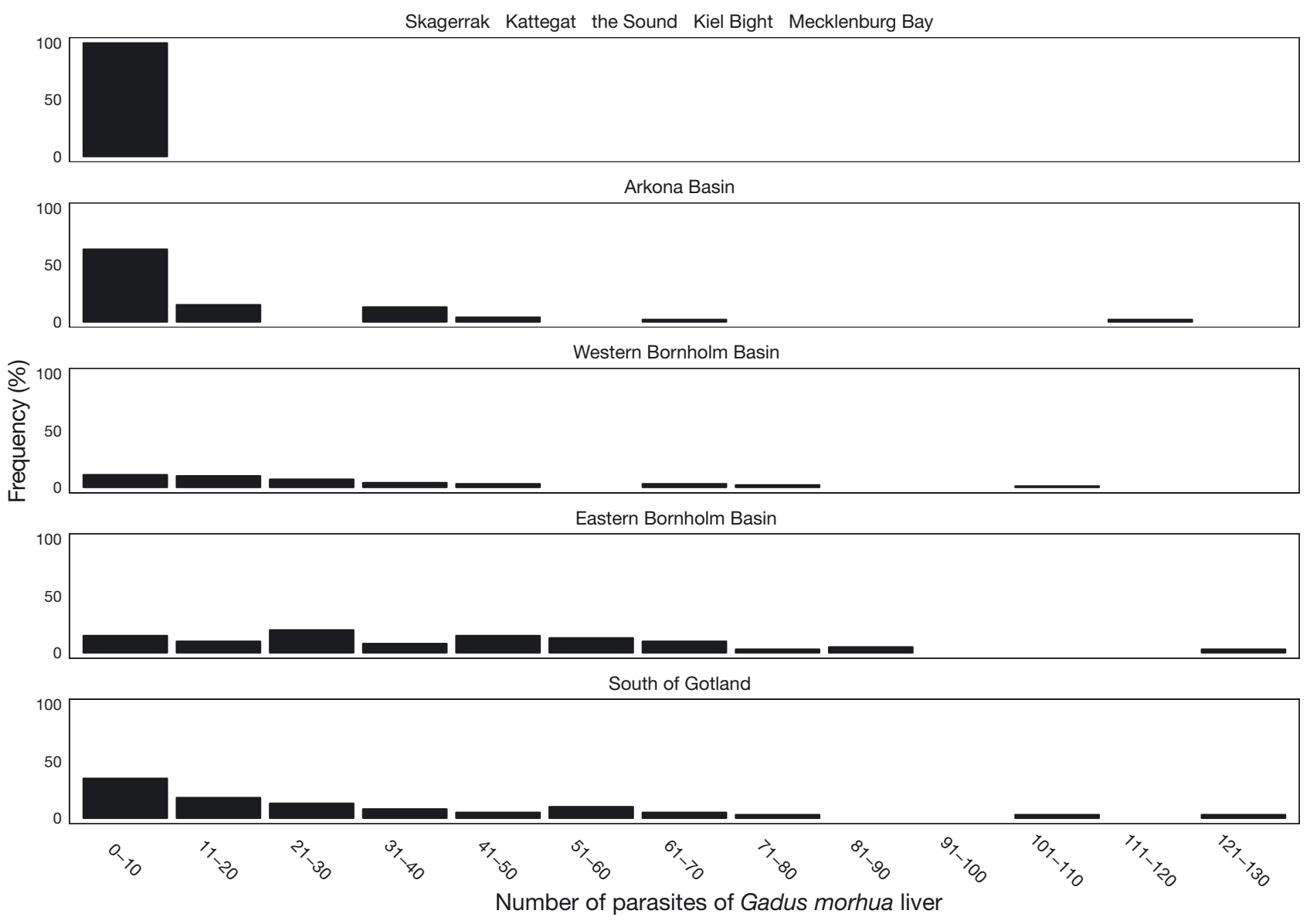

Fig. 5. Frequency distribution diagrams of Contracaecum osculatum in Gadus morhua livers in the 9 areas

G. morhua carrying from 0 to 10 C. osculatum in their liver while a single individual carried 113 parasites, resulting in the highest VMR for that area (31.4).

\section{Nematodes other than C. osculatum in G. morhua livers}

Of the 3830 parasites analysed in the 3 central Baltic areas (western and eastern parts of the Bornholm Basin and south of Gotland), only 6 specimens were not $C$. osculatum $(<0.002 \%)$. Three of these could not be identified, 1 was herring or whale worm Anisakis simplex (Rudolphi, 1809), and the remaining 2 were Hysterothylacium aduncum (Rudolphi, 1802). No parasites were found in the livers of $G$. morhua from Kiel Bight, and only 1 (unidentifiable) parasite besides C. osculatum was found in Mecklenburg Bay. The highest number of parasites other than C. osculatum (a subsample of 15 was confirmed by sequencing) was found in $G$. morhua livers from the Sound, with 1 A. simplex, $2 H$. aduncum and
6 seal worm or cod worm Pseudoterranova decipiens (Krabbe, 1878), which were species confirmed by sequencing, in addition to 8 unidentifiable parasites. In Kattegat, 7 unidentifiable and $3 A$. simplex were found. In Skagerrak, 2 A. simplex and $3 H$. aduncum (species confirmed by DNA sequencing) were found.

\section{Seal distribution}

From Skagerrak to the central Baltic Sea, the number of Halichoerus grypus increases by orders of magnitude, while Phoca vitulina display the opposite pattern (Fig. 6). P. vitulina are abundant in the Skagerrak and Kattegat, with around 15000 individuals along the Swedish and Norwegian coasts and the Danish islands. In the Sound and the Danish straits, $P$. vitulina density is much lower. Further east, they are rare, except for an isolated population in Kalmarsund, in the northern central Baltic.

In contrast, $H$. grypus are rare in the Skagerrak and Kattegat (only 10-25 along the entire Swedish 


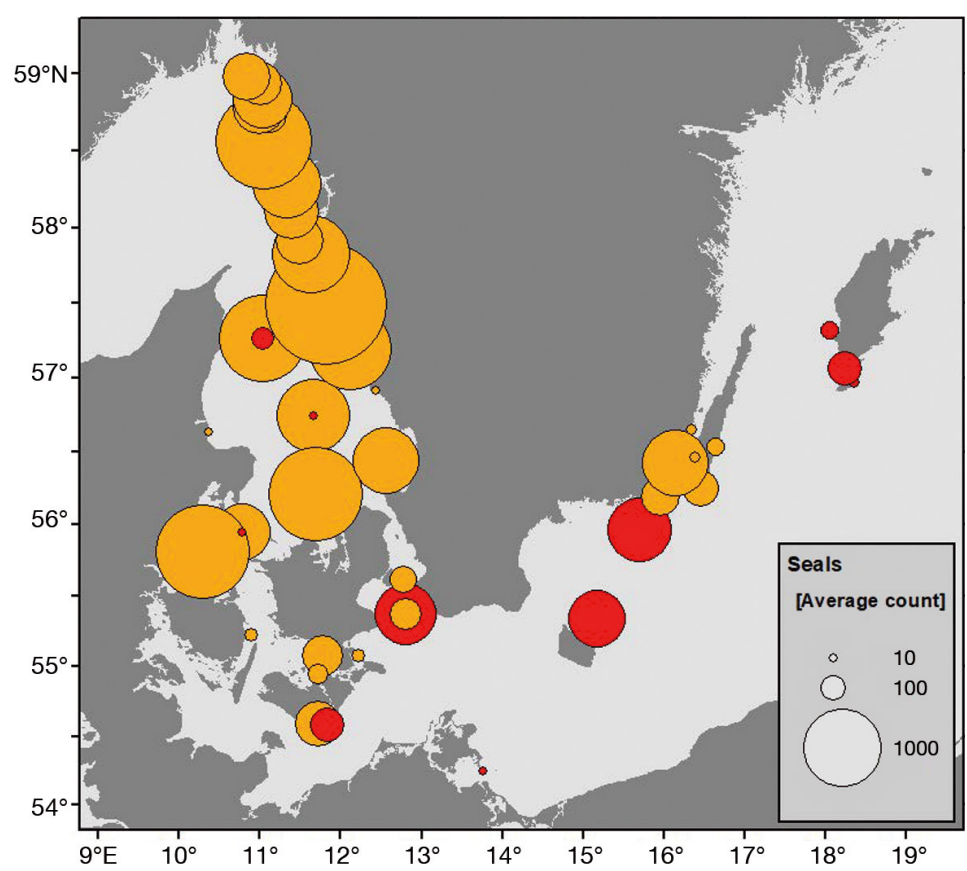

Fig. 6. Distribution of Halichoerus grypus (red) and Phoca vitulina (orange) on haul-outs based on surveys during their respective moulting seasons. Data from Denmark and Germany are from 2015-2017, data from Sweden are from 2015-2016

west coast north of Skåne, counted outside the grey seal moulting season; M. Ahola pers. comm.), and only around $100 \mathrm{H}$. grypus were counted in the Danish Kattegat. The most important haul-outs of $H$. grypus in the western Baltic are found at Falsterbo at the border between the Sound and the Arkona Basin and Rødsand in the northern Mecklenburg Bay. Further, into the Baltic, there are important haul-outs at Christiansø and Utklippan in the central Baltic as well as off southern Gotland with hundreds of individuals at the haul-outs.

\section{DISCUSSION}

Our study reveals a clear spatial pattern in prevalence and abundance of infection with Contracaecum osculatum s.s. in Gadus morhua livers sampled along a transect from the Skagerrak to the central part of the Baltic Sea, with highest levels of infection in the low-salinity areas from the Western Bornholm Basin to the south of Gotland. The high prevalence and abundance of C. osculatum in G. morhua livers in the Western Bornholm Basin are in line with Haarder et al. (2014), whereas we show for the first time that infection levels are equally severe further eastwards in the central Baltic. We also reveal that
C. osculatum infection is less prevalent for $G$. morhua in the more westerly areas with higher salinities, comprising the western Baltic, the Sound, the Kattegat and the Skagerrak. As the fish in Kiel Bight and Mecklenburg Bay were considerably larger and almost without $C$. osculatum in the livers, we found (contrary to initial expectations) a negative correlation between TL and abundance of infection when considering the entire data set. When looking solely at fish from the 3 areas in the central Baltic, no correlation between TL and abundance of infection was found (data not shown). Thus, our selected size range of G. morhua $(35-50 \mathrm{~cm})$ did not introduce any relevant bias to our results.

Notably, G. morhua caught in the Arkona Basin showed pronounced inter-individual variation, with an infection pattern between that of the eastern and western areas, i.e. some individuals had very high numbers of $C$. osculatum in the liver whereas others had none or few parasites. The Arkona Basin is a mixing area for the western and the eastern Baltic stocks of G. morhua, i.e. individuals from both stocks co-occur in this area (Hüssy et al. 2016). The present genetic assignment results strongly suggest that the difference in infection patterns is linked to the population of origin, and shows that this region comprises a mixture of G. morhua stocks with high and low burdens of C. osculatum. Thus, on an overall geographical scale, patterns of infection aligned well with the geographical distributions of the 2 main Baltic Sea G. morhua populations, with eastern Baltic fish showing higher levels of infection than western Baltic conspecifics.

In addition, the present data are in agreement with similar studies, revealing that a substantial proportion of G. morhua from the central Baltic Sea are in poor nutritional state. This pattern of low condition coincides with the highest numbers of $C$. osculatum in the livers of the most eastern fish. However, the degree to which this is a causal correlation is not deducible with the present sampling design, but should be investigated preferably through controlled experiments, or appropriate field sampling designs. Whether fish already in poor condition may be more susceptible to infection also warrants future elucidation.

The clear area effect displayed by increased prevalence and abundance of infection with $C$. osculatum in G. morhua livers towards the central Baltic coincides with parallel spatial trends in (1) seal species composition and abundance, (2) salinity and (3) differences in prey fields and resulting differences in the feeding ecology of G. morhua and seals. There 
may be inter-correlations among these factors, and they may also correlate with other factors that actually influence infection in addition to or instead of the investigated factors. Yet they may, alone or in combination, help to explain the observed differences in infection between east and west.

\section{Seals}

Seals are a prerequisite for C. osculatum, as they act as final host for the parasite (Køie \& Fagerholm 1995, Zuo et al. 2018). Distribution of Halichoerus grypus overlaps to some extent with the areas with greater infection levels and higher abundances of $C$. osculatum in G. morhua livers, while the Phoca vitulina distribution seems inversely related to infection levels. This minor role of $P$. vitulina may be explained by their suitability as the final host of this parasite species. Studies by Lunneryd (1991) indicated that $P$. vitulina in the area covering Skagerrak, Kattegat and the Baltic carry very few adult C. osculatum parasites, whereas H. grypus in the Baltic may carry more than 1000 adult individuals (Lunneryd et al. 2015, Zuo et al. 2018). P. vitulina, on the contrary, host many Pseudoterranova decipiens, the life cycle of which seems constrained by the lower salinities in the easternmost areas of the Baltic (Buchmann \& Kania 2012). This complies well with our results, revealing $P$. decipiens in livers from G. morhua in the Sound, but not in the easternmost areas.

There are important haul-outs with hundreds of $H$. grypus individuals counted in Mecklenburg Bay and in the Arkona Basin; nevertheless, the infection of $G$. morhua livers with $C$. osculatum in these areas was lower than in the central Baltic. However, telemetry studies of $H$. grypus equipped with GPS tags at these localities have also revealed that movements to the north and west from the haul-outs are limited while the tagged seals make frequent and much longer forays further into the Baltic (Dietz et al. 2015). If occurrence of $H$. grypus is the main limiting factor for local infection levels of $G$. morhua livers by C. osculatum, it should be expected that the areas presently showing low infection levels would become more heavily affected in the future. Historical sources and archaeological evidence indicate that $H$. grypus was the most common seal species in the Kattegat and the inner Danish waters and that culling campaigns and hunting shifted the balance in favour of $P$. vitulina (Olsen et al. 2018). In the absence of these pressures, it is likely that $H$. grypus will recolonize these areas in larger numbers.

\section{Salinity}

Salinity may also be a driving factor for the observed spatial differences. Aquatic species that are adapted to and thrive in brackish waters are potentially challenged physiologically in marine waters, resulting in reduced performance and survival (Behrens et al. 2017). The present study areas display a steep salinity gradient, from the brackish central Baltic Sea to the oceanic Skagerrak. The distribution of C. osculatum in marine fishes includes fully marine areas in the North Atlantic (Greenland, Iceland) but it cannot be excluded that the present nematode sibling species C. osculatum s.s. is favoured by lower salinities as found in the Baltic. This complies with both lower prevalence and abundance of C. osculatum in some marine waters. Studies have reported no or low (5-10\%) prevalence of C. osculatum in the highly saline central North Sea, the Celtic Sea, the Irish Sea and Icelandic waters (Perdiguero-Alonso et al. 2008, Gay et al. 2018). Notably, we only investigated livers in the present study and no other parts of the viscera, and recent investigations have shown that at least in the Barents Sea, different sibling species of C. osculatum (C. osculatum B) may favour sites other than the liver (K. MacKenzie unpubl. data). However, besides salinity, a series of other ecological factors differ between the North Atlantic and the Baltic, and controlled life cycle studies are required to elucidate the association between salinity and life cycle success of C. osculatum. Although the Kiel Bight - with intermediate salinity conditions was the only area in the present study where no $C$. osculatum was found in G. morhua livers, it is also relatively distant from $H$. grypus haul-out areas.

\section{Prey fields and feeding ecology}

Besides seals and salinity, dissimilarities in prey fields of $G$. morhua between east and west and the resulting differences in feeding ecology of the fish may also explain the difference in levels of infection with $C$. osculatum. As mentioned above, the 9 study areas comprise a transition zone between the marine North Sea and the brackish Baltic Sea, with higher salinities in the west and lower salinities in the east. Many species meet their physiological limits along this salinity gradient, resulting in a higher species richness in the west as compared to the east, including both benthos and fish (Bonsdorff 2006, Pecuchet et al. 2016) which constitute the main prey items of G. morhua. In fact, this difference is reflected in the 
diet composition of the fish, which is rather diverse in the western areas. Here, it includes high shares of benthic invertebrates such as different crustaceans (mainly the common shore crab Carcinus maenas, Linnaeus), but also molluscs (mainly bivalves) and Annelida at all depth strata as well as various fish species, while herring Clupea harengus (Linnaeus) and Sprattus sprattus only constitute a minor share (Funk 2017). In contrast, the feeding ecology of $G$. morhua in the lower saline central Baltic is quite different. Due to physiological constraints at low salinity, C. maenas abundance sharply decreases eastwards (Maagard \& Rheinheimer 1974, Dries \& Adelung 1982). Instead, the isopod Saduria entomon (Linnaeus) has historically been an important benthic prey of G. morhua in these more eastern areas of the Baltic. However, expanding hypoxic areas in recent years in the central Baltic Sea (Hinrichsen et al. 2011) have resulted in reduced availability of key benthic invertebrate prey species such as $S$. entomon, increasing the reliance of G. morhua on abundant piscine prey, in particular $S$. sprattus, and to a lesser extent $C$. harengus (Pachur \& Horbowy
2013, Casini et al. 2016). S. sprattus was recently identified as a major transport host of C. osculatum in the central Baltic, and increasing size-specific infection coincided with $G$. morhua sizes at which increasing shares of $S$. sprattus are included in their diet (Zuo et al. 2016). This may have contributed to higher infection rates of $G$. morhua in the central Baltic.

In addition, even though information about $H$. grypus diets in our study area is relatively limited, there are also indications that the diet of $H$. grypus in the western areas is more diverse than in the eastern areas where the main prey species are C. harengus, G. morhua and S. sprattus (Zrust 2017, Scharff-Olsen et al. in press). In summary and as depicted schematically in Fig. 7, the trophic interlinkages between seals, S. sprattus and G. morhua are much stronger in the eastern than in the western areas. This may lead to a higher and faster transfer of parasites between the involved species in the eastern areas, which could in turn explain the pronounced area effect in prevalence and abundance of infection observed in the present study.
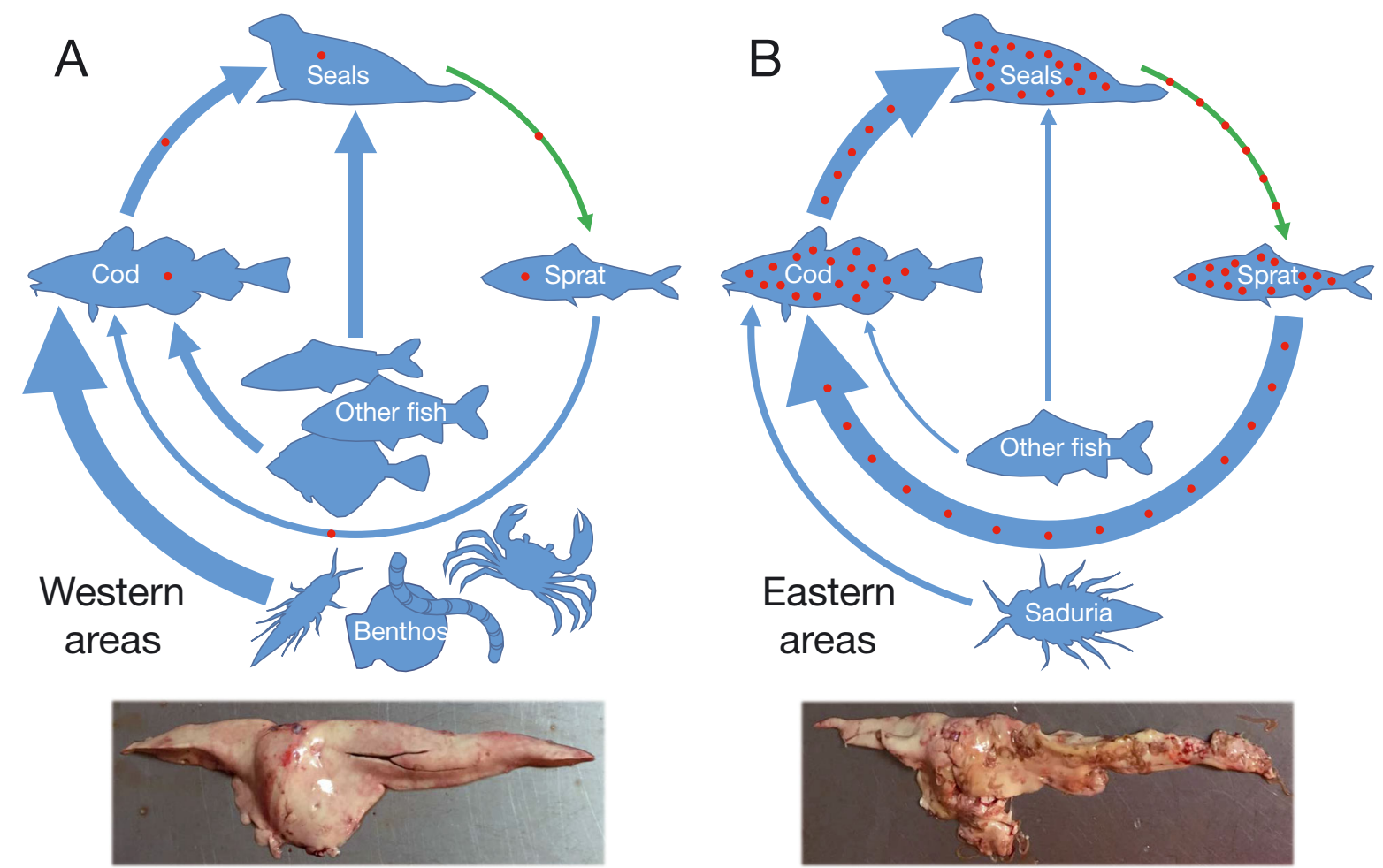

Fig. 7. Potential effects of variable prey composition of Gadus morhua and seals on their parasite load in (A) western and (B) eastern Baltic areas. Red dots = parasites, blue arrows = direct predation, green arrows = transport of parasites via indirect predation (i.e. parasite larvae released with seal faeces and ingested first by copepods or other zooplankton taxa and then by sprat). The width of the arrows indicates differences in the ingested proportions of different prey types. Photographs show examples of little (left) and heavily infected (right) G. morhua livers from western and eastern areas, respectively (photos by B. Huwer) 


\section{Condition factor}

Long-term data reveal a substantial and persistent deterioration of the nutritional state of $G$. morhua in the central Baltic since the 1990s, and in 2011, $15 \%$ of the fish $(40-60 \mathrm{~cm})$ were in poor nutritional state (Fulton's $K<0.8$ ) (Hinrichsen et al. 2011, Eero et al. 2012, Casini et al. 2016, Reusch et al. 2018). Our results comply well with this, as we found on average $20 \%$ of $G$. morhua to be in poor nutritional state in the eastern areas. Several factors may explain this poor health status. Firstly, there is a spatial mismatch between G. morhua and $S$. sprattus, presently the main prey of G. morhua (Eero et al. 2012, Casini et al. 2016, Reusch et al. 2018). Secondly, expanding hypoxia in recent years has led to reduced abundance of benthic prey (Pachur \& Horbowy 2013, Casini et al. 2016, Reusch et al. 2018). The expanding hypoxia furthermore places increased energetic demands on the fish when they have to rely, at least partly, on anaerobic energy production when staying in oxygen-poor waters, with a subsequent oxygen debt to be payed (Plambech et al. 2013, Casini et al. 2016, Behrens et al. 2018). Interestingly, however, the decline in the health status of $G$. morhua seems to be most pronounced for the larger individuals (Casini et al. 2016), which are also the ones most heavily infected with $C$. osculatum (Horbowy et al. 2016, Zuo et al. 2016). Horbowy et al. (2016) have recently shown that G. morhua containing many C. osculatum in their livers have lower condition as compared to conspecifics free of this parasite. Many liver parasites challenge liver integrity, and malfunctioning of this key organ, which aids in digestion and serves as a storage site for fats and carbohydrates (Bruslè \& Anadon 1996), may have direct adverse effects on health and condition. Natural mortality is assumed to be higher in G. morhua with poor condition (Dutil \& Lambert 2000, Swain \& Benoît 2015), and a high parasite load may push individual fish towards such poor health status that recovery is impossible (Horbowy et al. 2016). Alternatively, or contributing to this, G. morhua with heavy infections (and poorer condition) may exhibit reduced swimming performance, leading to a higher natural mortality (e.g. by seal predation) or higher fishing mortality by trawls. For instance, infection with $P$. decipiens reduced swimming performance in European smelt Osmerus eperlanus (Linnaeus) and European eel Anguilla anguilla (Linnaeus), leading to increased natural mortality in the wild (Sprengel \& Lüchtenberg 1991, McClelland 1995, Rohlwing et al. 1998).

\section{CONCLUSIONS}

Our findings reveal a significant difference in prevalence and abundance of infection with C. osculatum s.s. in G. morhua livers between the eastern and western areas, with highest levels of infection in G. morhua from the central Baltic as compared to the western Baltic, the Sound, Kattegat and Skagerrak. Future studies should investigate if this pattern is consistent independent of season. Highest abundances of C. osculatum coincided with lower nutritional condition of the fish. However, whether a causal link between abundance of infection and nutritional condition exists remains to be investigated. Although we cannot rule out other factors, abundance of $H$. grypus, salinity and prey field are potential factors driving the different infection levels. With currently increasing numbers of $H$. grypus in western areas, G. morhua here may be prone to higher levels of infection in the coming years. Interestingly, eastern and western Baltic G. morhua (as assigned by genetics) mixing in the Arkona Basin had a clear signature with higher and lower C. osculatum abundance in their livers, respectively. Combining genetics for population identification and infection to track migration (MacKenzie \& Hemmingsen 2015) might be a useful approach in the future.

Acknowledgements. We thank Casper Willestofte Berg (DTU Aqua) for assistance with data analysis, and we are grateful to the technical staff involved in sampling and sample processing at sea and in the laboratories. This project has received funding from the European Union's Horizon 2020 research and innovation programme under Grant Agreement No. 773713 (PANDORA), from the European Maritime and Fisheries Fund and The Danish Fisheries Agency (grants 33113-B-16-070 and 33113-B-16-071), from the BONUS BaltHealth, which has received funding from BONUS (Art. 185), funded jointly by the EU, Innovation Fund Denmark (grants 6180-00001B and 6180-00002B), Forschungszentrum Jülich $\mathrm{GmbH}$, German Federal Ministry of Education and Research (grant FKZ 03F0767A), Academy of Finland (grant 311966) and Swedish Foundation for Strategic Environmental Research (MISTRA), and from The Danish Ministry for Food, Agriculture and Fisheries and the European Union through the projects 'Improved management based on stock identification of eastern and western Baltic cod' (European Fisheries Fund: contract No. 3744-11-k-0216), 'Optimal sustainable use of cod stocks available for Danish fisheries' (European Fisheries Fund: contract No. 33010-13-k-0269) and 'Sustainable management of Kattegat cod; improved knowledge on population components and migration' (European Maritime and Fisheries Fund: contract No. 33113-B-16034). In addition, support was also provided by the BONUS BIO-C3 project, supported by BONUS (Art 185), funded jointly by the EU and the BMBF through Forschungszentrum Jülich (Germany) and the Innovation Fund Denmark. 


\section{LITERATURE CITED}

Barber I, Hoare D, Krause J (2000) Effects of parasites on fish behaviour: a review and evolutionary perspective. Rev Fish Biol Fish 10:131-165

Behrens JW, van Deurs M, Christensen EAF (2017) Evaluating dispersal potential of an invasive fish by the use of aerobic scope and osmoregulation capacity. PLOS ONE 12:e0176038

Behrens JW, Svendsen JC, Neuenfeldt S, Andersen NG, van Deurs M (2018) Individual variation in aerobic scope affects modeled vertical foraging migration in Atlantic cod Gadus morhua, but only in moderate hypoxia. Mar Ecol Prog Ser 599:201-208

Bonsdorff E (2006) Zoobenthic diversity-gradients in the Baltic Sea: continuous post-glacial succession in a stressed ecosystem. J Exp Mar Biol Ecol 330:383-391

Brattey J, Bishop CA, Myers RA (1990) Geographic distribution and abundance of Pseudoterranova decipiens (Nematoda: Ascaridoidea) in the musculature of Atlantic cod, Gadus morhua, from Newfoundland and Labrador. Can Bull Fish Aquat Sci 222:67-82

Bruslè J, Anadon GG (1996) The structure and function of fish liver. In: Datta Munshi JS, Dutta HM (eds) Fish morphology. Science Publishers, Lebanon, NH, p 77-93

Buchmann K (2007) An introduction to fish parasitological methods - classical and molecular techniques. Biofolia Press, Frederiksberg

Buchmann K, Kania PW (2012) Emerging Pseudoterranova decipiens (Krabbe, 1878) problems in Baltic cod, Gadus morhua L., associated with grey seal colonization of spawning grounds. J Fish Dis 35:861-866

Bush AO, Lafferty KD, Lotz JM, Shostak AW (1997) Parasitology meets ecology on its own terms: Margolis et al. revisited. J Parasitol 83:575-583

Casini M, Käll F, Hansson M, Plikshs M and others (2016) Hypoxic areas, density-dependence and food limitation drive the body condition of a heavily exploited marine fish predator. R Soc Open Sci 3:160416

Dezfuli BS, Fernandes CE, Galindo GM, Castaldelli G and others (2016a) Nematode infection in liver of the fish Gymnotus inaequilabiatus (Gymnotiformes: Gymnotidae) from the Pantanal region in Brazil: pathobiology and inflammatory response. Parasit Vectors 9:473

Dezfuli BS, Manera M, Bosi G, De Pasquale JA, D'Amelio S, Castaldelli G, Giari L (2016b) Anguilla anguilla intestinal immune response to natural infection with Contracaecum rudolphii A larvae. J Fish Dis 39:1187-1200

Dietz R, Galatius A, Mikkelsen L, Nabe-Nielsen J and others (2015) Marine mammals - investigations and preparation of environmental impact assessment for Kriegers Flak Offshore Wind Farm. https://ens.dk/sites/ens.dk/ files/Vindenergi/kriegers_flak_offshore_wind_farm_eia_ marine_mammals_technical_report.pdf

* Dries M, Adelung D (1982) Die Schlei, ein Modell für die Verbreitung der Strandkrabbe Carcinus maenas. Helgol Meeresunters 35:65-77

Dutil JD, Lambert Y (2000) Natural mortality from poor condition in Atlantic cod (Gadus morhua). Can J Fish Aquat Sci 57:826-836

Eero M, Vinther M, Haslob H, Huwer B, Casini M, StorrPaulsen M, Köster FW (2012) Spatial management of marine resources can enhance the recovery of predators and avoid local depletion of forage fish. Conserv Lett 5: 486-492
Eero M, Hemmer-Hansen J, Hüssy K (2014) Implications of stock recovery for a neighbouring management unit: experience from the Baltic cod. ICES J Mar Sci 71: 1458-1466

Eero M, Hjelm J, Behrens J, Buchmann K and others (2015) Eastern Baltic cod in distress: biological changes and challenges for stock assessment. ICES J Mar Sci 72: 2180-2186

Fagerholm HP (1982) Parasites of fish in Finland. VI. Nematodes. Acta Acad Abo Ser B 40:1-128

Fietz K, Galatius A, Teilmann J, Dietz R and others (2016) Shift of grey seal subspecies boundaries in response to climate, culling and conservation. Mol Ecol 25: 4097-4112

Funk S (2017) Depth-specific patterns in distribution and food intake of cod (Gadus morhua) in the western Baltic Sea. MSc thesis, University of Hamburg

*Galatius A, Ahola M, Härkönen T, Jüssi I, Jüssi M, Karlsson O, Verevkin M (2014) Guidelines for seal abundance monitoring in the HELCOM area. www.helcom.fi/actionareas/monitoring-and-assessment/manuals-and-guidelines/seal-abundance-guidelines

Gay M, Bao M, MacKenzie K, Pascual S and others (2018) Infection levels and species diversity of ascaridoid nematodes in Atlantic cod, Gadus morhua, are correlated with geographic area and fish size. Fish Res 202:90-102

*Haarder S, Kania PW, Galatius A, Buchmann K (2014) Increased Contracaecum osculatum infection in Baltic cod (Gadus morhua) livers (1982-2012) associated with increasing grey seal (Halichoerus gryphus [sic]) populations. J Wildl Dis 50:537-543

* Hårding KC, Härkönen T, Helander B, Karlsson O (2007) Status of Baltic grey seals: population assessment and extinction risk. NAMMCO Sci Publ 6:33-56

HELCOM (2017) Distribution of Baltic seals. HELCOM core indicator report. www.helcom.fi/Core\%20Indicators/ Distribution \% 20of\%20Baltic \% 20seals \% 20HELCOM\% 20core\%20indicator\%202018.pdf (accessed 2 May 2018)

*Hinrichsen $\mathrm{HH}$, Huwer B, Makarchouk A, Petereit C, Schaber M, Voss R (2011) Climate-driven long-term trends in Baltic Sea oxygen concentrations and the potential consequences for eastern Baltic cod (Gadus morhua). ICES J Mar Sci 68:2019-2028

* Horbowy J, Podolska M, Nadolna-Ałtyn K (2016) Increasing occurrence of anisakid nematodes in the liver of cod (Gadus morhua) from the Baltic Sea: Does infection affect the condition and mortality of fish? Fish Res 179:98-103

*Hüssy K, Hinrichsen HH, Eero M, Mosegaard H, Hansen JH, Lehmann A, Lundgaard LS (2016) Spatio-temporal trends in stock mixing of eastern and western Baltic cod in the Arkona Basin and the implications for recruitment. ICES J Mar Sci 73:293-303

ICES WGMME (2018) Report of the Working Group on Marine Mammal Ecology (WGMME) 19-22 February 2018, La Rochelle, France

Køie M, Fagerholm HP (1995) The life cycle of Contracaecum osculatum (Rudolphi, 1802) sensu stricto (Nematoda, Ascaridoidea, Anisakidae) in view of experimental infections. Parasitol Res 81:481-489

Köster FW, Huwer B, Hinrichsen HH, Neumann V and others (2017) Eastern Baltic cod recruitment revisiteddynamics and impacting factors. ICES J Mar Sci 74:3-19

* Lunneryd SG (1991) Anisakid nematodes in the harbour seal Phoca vitulina from the Kattegat-Skagerrak and the Baltic. Ophelia 34:105-115 
Lunneryd SG, Boström MK, Aspholm PE (2015) Sealworm Pseudoterranova decipiens infection in grey seal Halichoerus grypus, cod Gadus morhua and shorthorn sculpin Myoxocephalus scorpius in the Baltic Sea. Parasitol Res 114:257-264

Maagard L, Rheinheimer G (1974) Meereskunde der Ostsee. Springer, Berlin

MacKenzie K, Hemmingsen W (2015) Parasites as biological tags in marine fisheries research: European Atlantic waters. Parasitology 142(Spec Issue 1):54-67

Marcogliese DJ, Pietrock M (2011) Combined effects of parasites and contaminants on animal health: parasites do matter. Trends Parasitol 27:123-130

Marteinsdottir G, Begg GA (2002) Essential relationships incorporating the influence of age, size and condition on variables required for estimation of reproductive potential in Atlantic cod Gadus morhua. Mar Ecol Prog Ser 235:235-256

McClelland G (1995) Experimental infection of fish with larval sealworm, Pseudoterranova decipiens (Nematoda, Aniskinae), transmitted by amphipods. Can J Fish Aquat Sci 52:140-155

Mehrdana F, Bahlool QZ, Skov J, Marana MH, Sindberg D, Mundeling M, Buchmann K (2014) Occurrence of zoonotic nematodes Pseudoterranova decipiens, Contracaecum osculatum and Anisakis simplex in cod (Gadus morhua) from the Baltic Sea. Vet Parasitol 205: 581-587

Nadolna K, Podolska M (2014) Anisakid larvae in the liver of cod (Gadus morhua) from the southern Baltic Sea. J Helminthol 88:237-246

Nielsen EE, Cariani A, Mac Aoidh E, Maes GE and others (2012) Gene-associated markers provide tools for tackling illegal fishing and false eco-certification. Nat Commun 3:851

兴Olsen MT, Galatius A, Härkönen T (2018) The history and effects of seal-fishery conflicts in Denmark. Mar Ecol Prog Ser 595:233-243

Ovegård M, Berndt K, Lunneryd SG (2012) Condition indices of Atlantic cod (Gadus morhua) biased by capturing method. ICES J Mar Sci 69:1781-1788

* Pachur ME, Horbowy J (2013) Food composition and prey selection of cod, Gadus morhua (Actinopterygii: Gadiformes: Gadidae), in the Southern Baltic Sea. Acta Ichthyol Piscat 43:109-118

Pecuchet L, Törnroos A, Lindegren M (2016) Patterns and drivers of fish community assembly in a large marine ecosystem. Mar Ecol Prog Ser 546:239-248

Perdiguero-Alonso D, Montero FE, Raga JA, Kostadinova A (2008) Composition and structure of the parasite faunas of cod, Gadus morhua L. (Teleostei: Gadidae), in the North East Atlantic. Parasit Vectors 1:23

* Piry S, Alapetite A, Cornuet JM, Paetkau D, Baudouin L, Estoup A (2004) GeneClass2: a software for genetic as-

Editorial responsibility: Alistair Hobday,

Hobart, Tasmania, Australia signment and first-generation migrant detection. J Hered 95:536-539

*Plambech M, van Deurs M, Steffensen JF, Tirsgaard B, Behrens JW (2013) Excess post-hypoxic oxygen consumption in Atlantic cod Gadus morhua. J Fish Biol 83:396-403

Rannala B, Mountain JL (1997) Detecting immigration by using multilocus genotypes. Proc Natl Acad Sci USA 94: 9197-9201

Reusch TBH, Dierking J, Andersson HC, Bonsdorff E and others (2018) The Baltic Sea as a time machine for the future coastal ocean. Sci Adv 4:eaar8195

Kohlwing T, Palm HW, Rosenthal H (1998) Parasitation with Pseudoterranova decipiens (Nematoda) influences the survival rate of the European smelt Osmerus eperlanus retained by a screen wall of a nuclear power plant. Dis Aquat Org 32:233-236

* Scharff-Olsen C, Galatius A, Teilmann J, Dietz R and others (in press) Diet of seals in the Baltic Sea region: a synthesis of published and new data from 1968 to 2013. ICES J Mar Sci

Sprengel G, Lüchtenberg H (1991) Infection by endoparasites reduces maximum swimming speed of European smelt Osmerus eperlanus and European eel Anguilla anguilla. Dis Aquat Org 11:31-35

* Swain DP, Benoît HP (2015) Extreme increases in natural mortality prevent recovery of collapsed fish populations in a Northwest Atlantic ecosystem. Mar Ecol Prog Ser 519:165-182

Upton G, Cook I (2006) Oxford dictionary of statistics, 2nd edn. Oxford University Press, Oxford

Valtonen ET, Fagerholm HP, Helle E (1988) Contracaecum osculatum (Nematoda: Anisakidae) in fish and seals in Bothnian Bay (northeastern Baltic Sea). Int J Parasitol 18: 365-370

Zhu XQ, Podolska M, Liu JS, Yu HQ and others (2007) Identification of anisakid nematodes with zoonotic potential from Europe and China by single-strand conformation polymorphism analysis of nuclear ribosomal DNA. Parasitol Res 101:1703-1707

Zrust M (2017) Assessment of grey seal (Halichoerus grypus) diet composition in the western Baltic Sea. MSc thesis, Technical University of Denmark, Kongens Lyngby

Zuo S, Huwer B, Bahlool Q, Al-Jubury A and others (2016) Host size-dependent anisakid infection in Baltic cod Gadus morhua associated with differential food preferences. Dis Aquat Org 120:69-75

* Zuo S, Barlaup L, Mohammadkarami A, Al-Jubury A, Chen D, Kania PW, Buchmann K (2017) Extrusion of Contracaecum osculatum nematode larvae from the liver of cod (Gadus morhua). Parasitol Res 116:2721-2726

Zuo S, Kania PW, Mehrdana F, Marana MH, Buchmann K (2018) Contracaecum osculatum and other anisakid nematodes in grey seals and cod in the Baltic sea: molecular and ecological links. J Helminthol 92:81-89

Submitted: July 10, 2018; Accepted: October 2, 2018

Proofs received from author(s): October 30, 2018 